\title{
Incidence and reasons for leave against medical advice among orthopedic and trauma patients at the university college hospital Ibadan
}

\author{
Tolulope O. Ogunrewo, Oluwadayo A. Magbagbeola*, Samuel T. Oladejo, Adeoye Allen-Taylor
}

Department of Orthopedics and Trauma, University College Hospital, Ibadan, Oyo State, Nigeria

Received: 08 September 2020

Revised: 12 October 2020

Accepted: 10 November 2020

\section{*Correspondence:}

Dr. Oluwadayo A. Magbagbeola,

E-mail: oamagbagbeola@gmail.com

Copyright: (c) the author(s), publisher and licensee Medip Academy. This is an open-access article distributed under the terms of the Creative Commons Attribution Non-Commercial License, which permits unrestricted non-commercial use, distribution, and reproduction in any medium, provided the original work is properly cited.

\section{ABSTRACT}

Background: Leave against medical advice (LAMA) of hospitalized patients is an adverse clinical event in which a patient chooses to leave the hospital before it is medically advisable to do so and it negatively affects the treatment outcome. Because of this, the study was designed to determine the incidence of and indications for LAMA among orthopedic patients who presented at the accident and emergency department of the university college hospital, Ibadan. Methods: This was a prospective hospital-based study determining the incidence of LAMA among orthopedic patients who presented at the accident and emergency department of the university college hospital, Ibadan between September 2019 and March 2020.

Results: A total of 289 patients with orthopedic conditions presented within the study period and about $12.46 \%$ of these LAMA. The male to female ratio observed in this study is $2: 1$. The age range was between 8 and 93 years. Trauma from motorbike and motor vehicle accidents accounted for over $80 \%$ of the etiology. The most important factor influencing LAMA is financial constraints $(63.9 \%)$ and LAMA was signed mostly by the patients $(25 \%)$.

Conclusions: LAMA among orthopedic patients in Ibadan is mostly due to financial reasons, therefore, factors that will reduce the cost of management such as the accessibility to health insurance schemes will significantly reduce the incidence of LAMA among orthopedic patients in Nigeria.

Keywords: LAMA, DAMA, Health insurance scheme

\section{INTRODUCTION}

Patients who leave the hospital before the clinician certification of fitness are said to have LAMA. ${ }^{1}$ LAMA otherwise referred to as discharge against medical advice (DAMA) or discharge at own risk (DAOR) of hospitalized patients is an adverse clinical event often resulting from a fundamental disagreement between the patient or an interested third party and the attending physician and/or the hospital environment care. ${ }^{2,3}$ LAMA is the situation in which a patient chooses to leave the hospital before it is medically advisable to do so and it involves the signing of a legal release form by the patient, caregiver or parent/guardian for children., ${ }^{4,5}$ This prevents such patients from having the full benefits of services rendered by the health facility as such these individuals place themselves at medical risk as observed by Jeremiah et al in their study. ${ }^{6,7}$

LAMA negatively impacts treatment outcomes, healthcare resource utilization and exposes the clinician as well as health care administrators to the hazards of litigations. ${ }^{8-10}$ It is also associated with higher readmission rates for the same or related morbidity and higher long-term financial cost of medical care. ${ }^{11,12}$

Patients have a right to decide to leave the hospital. Steven Stack, a member of the board of the American medical association opined that "medical decisions are a partnership between the patient and the doctor, but the 
patient is nearly always the final decision maker". ${ }^{11}$ Patients who leave the hospital against doctor's order have been reported to be at a higher risk of adverse health outcomes compared with patients who follow doctor's advice. ${ }^{11}$

The incidence of LAMA ranges from 0.2 to $2.25 \%$ of hospital admissions in developed societies. ${ }^{11,12}$ The rate ranged from 0.7 to $2.2 \%$ for general medical admissions, 6 to $54 \%$ for psychiatry admission and $0.9-4.2 \%$ for emergency admissions. ${ }^{1,3,13,14}$ The study done in Uyo, Nigeria showed a rate of $5.9 \%$ among orthopedic patients. $^{15}$

LAMA is influenced by some factors. These factors include patients' medical condition, the availability or otherwise of health insurance. ${ }^{9-11}$ It is observed to be more common in alcoholics and drug addicts as well as mentally and psychologically challenged patients. ${ }^{9}$

Some reasons given for LAMA include dissatisfaction with care, enticement/inducement by alternative medical practitioners/traditional bonesetters, sociocultural beliefs patient feeling better; family obligations, financial reasons and legal issues. ${ }^{10,16}$ Other factors such as younger age, male sex, substance abuse disorders and lack of health insurance have been noted. ${ }^{17}$ Also, high illiteracy rate in Nigeria and other parts of Africa may make comprehension of explanations as regards patient's health and patient care difficult and this may lead to a lack of trust in orthodox treatment. ${ }^{18}$

Patient non-compliance has the potential to result in harm to the individual's health and professional liability is also a concern for medical professional caring for these patients.

In children, it was observed that the commonest reason for LAMA is the parental fear of accumulation of hospital bills and this affects the health-seeking behaviour. ${ }^{5}$

Patients who LAMA usually patronize alternative medicine (i.e. traditional, trado-medical, spiritual healing homes and quack clinics) and some of the reason for this include ignorance, poverty and lack of proper healthcare plan. ${ }^{18-20}$
Because of this, the study was designed to determine the incidence of and indications of LAMA among orthopedic patients who presented at the accident and emergency department of the university college hospital, Ibadan, Oyo State, Nigeria.

\section{METHODS}

This was a prospective hospital-based study to determine the incidence of LAMA among orthopedics patients who presented at the accident and emergency department of the university college hospital Ibadan, an 850-bed tertiary hospital located in Ibadan, the capital of Oyo State in the Southwest of Nigeria. It included all consecutive patients admitted for orthopedic and extremity trauma-related consults who left against medical advice between September 2019 and March 2020. Data were obtained using a predesigned proforma which was administered by the orthopedic registrar on-call. Information retrieved included the patient's initials, age, occupation, sex, level of education, cause of fracture, type of fracture, diagnosis, duration of hospitalization before LAMA, the reason for LAMA and the signatory to the LAMA.

Data analysis was carried out using IBM SPSS statistics for Windows, version 20.0. (IBM Corp., Armonk, NY, USA).

\section{RESULTS}

A total of 289 orthopedics and trauma-related consults were requested during the study period with 36 of them leaving against medical advice. The ratio of males to females was 2 to 1 . The patients aged from 8-93 years, with the patients aged 20-29 years having the highest frequency of LAMAs followed by the 30-39 years (36 to 25\% respectively). Eighty-three per cent of the patients who LAMA was involved in road traffic crashes. Femur, tibia and fibula fractures were the highest among patients who LAMA followed by upper limb fractures (Table 1).

Almost all (97\%) of the patients who LAMA did so within the first 7 days of admission (70\% of these patients leave within the first 24 hours). Two-thirds of these patients LAMA due to inability to pay for care and $60 \%$ of the LAMAs were signed by family members (Table 2).

Table 1: Demographics and injury characteristics of orthopaedics and trauma patients who LAMA in the accident and emergency at $\mathrm{UCH}$, Ibadan $(\mathrm{n}=36)$.

\begin{tabular}{|l|l|}
\hline Characteristics & $\mathbf{N}(\%)$ \\
\hline Gender & $24(66.7)$ \\
\hline Male & 5 \\
\hline Age (years) & 13 \\
\hline 19 and younger & 9 \\
\hline $20-29$ & 4 \\
\hline $30-39$ & 5 \\
\hline $40-49$ & Continued. \\
\hline 50 and older & 5 \\
\hline
\end{tabular}




\begin{tabular}{|l|l|}
\hline Characteristics & $N(\%)$ \\
\hline Primary & $11(30.6)$ \\
\hline Secondary & $14(38.9)$ \\
\hline Tertiary & $8(22.2)$ \\
\hline None & $3(8.3)$ \\
\hline Diagnosis & $10(27.78)$ \\
\hline Femur fracture & $10(27.78)$ \\
\hline Tibia and fibula fractures & $4(11.11)$ \\
\hline Humerus fracture & $3(8.33)$ \\
\hline Radius and ulna fractures & $1(2.78)$ \\
\hline Diabetic foot syndrome & $2(5.56)$ \\
\hline Ankle fracture & $3(8.33)$ \\
\hline Floating knee & $1(2.78)$ \\
\hline Hip dislocation & $1(2.78)$ \\
\hline Open knee injury & $1(2.78)$ \\
\hline Foot injury & $18(50)$ \\
\hline Mechanism of injury & $12(33.3)$ \\
\hline Motor-vehicle road traffic accident & $5(13.9)$ \\
\hline Motor-bike road traffic accident & $1(2.8)$ \\
\hline Fall & \\
\hline Occupation-related & \\
\hline
\end{tabular}

Table 2: Days on admission before LAMA, the reason for and signatory to LAMA.

\begin{tabular}{|ll|}
\hline \multicolumn{2}{|l|}{ Variables } \\
\hline \multicolumn{2}{|l|}{ Days on admission before LAMA } \\
\hline 1 & $24(68.56)$ \\
\hline 2 & $5(14.29)$ \\
\hline 3 & $3(8.57)$ \\
\hline 4 & $1(2.86)$ \\
\hline 7 & $1(2.86)$ \\
\hline 14 & $1(2.86)$ \\
\hline Reason for LAMA & \\
\hline Financial & $24(66.7)$ \\
\hline Alternative care (TBS) & $9(25)$ \\
\hline Another facility & $1(2.8)$ \\
\hline Inadequate care & $2(5.6)$ \\
\hline Signatory to the LAMA & \\
\hline Self & $9(25)$ \\
\hline Father & $7(19.44)$ \\
\hline Mother & $2(5.56)$ \\
\hline Children & $2(5.56)$ \\
\hline Brother & $6(16.67)$ \\
\hline Sister & $2(5.56)$ \\
\hline Husband & $2(5.56)$ \\
\hline Friends & $6(16.67)$ \\
\hline N=36; $*$ n=35. & \\
\hline
\end{tabular}

\section{DISCUSSION}

According to human rights and the 'patients' charter', a patient has a right to self-determination or autonomy, while the healthcare providers also have the right to do what they think is best for the patient (to act with beneficence). ${ }^{6}$
A total of 289 patients with orthopedic conditions presented to the accident and emergency department of the university college hospital, Ibadan within the study period. 36 patients left the hospital against medical advice. This accounted for $12.46 \%$ of the patients with orthopedic and extremity trauma-related conditions. A similar study done in Uyo showed a lesser value of $5.9 \%$, while Udosen et al. ${ }^{15,21}$ found a rate of $72.2 \%$ among patients who presented with acute trauma in their study. The high cost of procuring health care services among Nigerians and poverty may be accountable for this higher rate of LAMA. This is because most Nigerians still pay out of pocket for their health as the health insurance scheme is not widely adopted. The male to female ratio observed in this study is $2: 1$. Udosen et al. ${ }^{21}$ in Calabar observed a similar finding while Nasir et al. ${ }^{1}$ observed a much higher ratio in their study. More males are involved in trauma, and acute trauma has been observed to be associated with a high rate of LAMA. ${ }^{22}$ This may be the reason for the higher prevalence of males in LAMA.

The age range is between 8 and 93 years, however, $61.1 \%$ had their age between 20 and 39 years. This age bracket suggests a significant effect and influence of economic and social pressure ${ }^{1}$ as such they are more predisposed to traumatic events thereby predisposed to LAMA.

About $90 \%$ of our patients who left against medical advice had some form of formal (primary, secondary or tertiary) education. $69.5 \%$ of them had their education up to the secondary school level. Most of the communication is done in English and local dialect as such failure to comprehend information concerning care and health may not significantly influence in or predispose these patients to LAMA. Trauma from motorbike and motor vehicle 
accidents accounted for over $80 \%$ of the etiology. Other studies also showed trauma as the main cause with the rate ranging between 63.9 and $97.2 \% .^{1,8,9} \mathrm{Road}$ traffic crash is common in our environment due to bad roads and poor road network, driving above the speed limit, inadequate road signs and driving under the influence of alcohol. Most of these patients left within the first days of admission. Similar studies done elsewhere in Nigeria showed most patients LAMA within the first five days of admission. ${ }^{15,21}$

Financial reason was the most given reason for LAMA in this study $(63.9 \%)$. This is as observed in the study done in Enugu, Nigeria. ${ }^{23}$ The health insurance in Nigeria is not yet as widely used especially by individuals in the informal sector of the economy as such most of these patients pay out of pocket. Also, in its present form, not all aspect of treatment is covered by the health insurance for those presently on it. Consequently, limited financial resources remains a major barrier to the delivery of quality healthcare in Nigeria as well as a major factor that predispose our patients to LAMA.

The desire for management at the traditional bonesetter (TBS) is the next most common reason for seeking discharge against medical advice as it accounted for $25 \%$. Similarly, other studies observed that most of the patients who LAMA did so to seek alternative/unorthodox treatment. ${ }^{1,16}$ This is because such individuals have more faith in the treatment by the TBS and the view that they are not as expensive as the orthodox methods of treatment make patients choose this form of treatment. Other reasons given include unsatisfactory care and need for treatment at another facility.

LAMA was signed by the patients in $25 \%$ of instances and by the family members (father, mother, siblings, children and spouses) in $58.3 \%$ of cases. $16.7 \%$ of LAMAs were signed by friends. This trend is similar to that found by Eze et al. ${ }^{23}$ This observation further shows the dominant role of the opinion of family members in influencing an individual's healthcare choices among Nigerians, as families and caregivers bear the cost of medical care due to poor or non-existent social security services. ${ }^{24}$

\section{CONCLUSION}

LAMA among orthopedic patients in Ibadan is a common event and is mostly due to financial reasons. Therefore, increasing access to health insurance schemes will significantly reduce the financial burden of care, reduce the incidence of LAMA and improve the outcome of patients with orthopedic problems in Nigeria.

Funding: No funding sources Conflict of interest: None declared

Ethical approval: The study was approved by the institutional ethics committee

\section{REFERENCES}

1. Nasir AA, Babalola OM. Clinical spectrum of discharges against medical advice in a developing country. Indian J Surg. 2008;70(2):68-72.

2. Franks P, Meldrum S, Fiscella K. Discharges against medical advice: Are race/ethnicity predictors? J Gen Intern Med. 2006;9:955-60.

3. Alebiosu CO, Raimi TH. A study of hospital patients' discharge against medical advice in the Ogun State University Teaching Hospital, Sagamu, Nigeria. Niger Med Pract. 2001;40:33-5.

4. Shirani F, Jalili M, Asl-e-Soleiman H. Discharged against medical advice from emergency department: results from a tertiary care hospital in Tehran, Iran. Eur J Emerg Med. 2010;17(6):318-21.

5. Onyiriuka AN. Discharge of hospitalized under-fives against medical advice in Benin City, Nigeria. Niger J Clin Pract. 2007;10(3):200-4.

6. Stern TW, Silverman BC, Smith FA, Stern TA. Prior discharges against medical advice and withdrawal of consent: what they can teach us about patient management. Prim Care Companion CNS Disord. 2011;13(1): PCC.10f01047.

7. Alfandre DJ. "I'm going home" discharges against medical advice. Mayo Clinic Proceedings. 2009;84(3):255-60.

8. Ohanaka EC. Discharge against medical advice. Trop Doct. 2002;32(3):149-51.

9. Akiode O, Musa AA, Shonubi AM, Salami BA, Oyelekan AA. Trends of discharges against medical advice in a suburban surgical practice in Nigeria. Trop Doct. 2005;35(1):51-2.

10. Pennycook AG, McNaughton G, Hogg F. Irregular discharge against medical advice from the accident and emergency department - a cause for concern. Emerg Med J. 1992;9(2):230-8.

11. Moyse HS, Osmum WE. Discharges against medical advice: a community hospital experience. Can J Rural Med. 2004;9(3):148-53.

12. Jankowski CB, Drum DE. Diagnostic correlates of discharge against medical advice. Arch Gen Psychiatry. 1977;34(2):153-5.

13. Anis AH, Sun H, Guh DP, Palepu A, Schechter MT, O'Shaughnessy MV. Leaving hospital against medical advice among HIV-positive patients. Can Med Assoc J. 2002;167(6):633-7.

14. Wong TW, Lee KM, Chan R, Lau CC. A study of patients who leave an accident and emergency department against medical advice. Hong Kong $\mathbf{J}$ Emerg Me. 2000;7(1):22-6.

15. Ngim NE, Nottidge T, Oku A, Akpan AF. Why do orthopaedic trauma patients leave hospital against medical advice? Ibom Med J. 2013;6(1):1-4.

16. Aliyu ZY. Discharge against medical advice: sociodemographic, clinical and financial perspectives. Int J Clin Pract. 2002;56(5):325-7.

17. Saitz R. Discharges against medical advice: time to address the causes. Can Med Assoc J. 2002; 167(6):647-8. 
18. Udosen AM, Ottei OO, Onuba O. Role of traditional bonesetters in Africa: experience in Calabar, Nigeria. Ann Afr Med. 2006;5(4):170-3.

19. Thanni LO. Factors influencing patronage of traditional bonesetters. W Afr J Med. 2000;19(3):2204.

20. Schlauch RW, Reich P, Kelly MJ. Leaving the hospital against medical advice. $\mathrm{N}$ Engl J Med. 1979;300(1):22-4.

21. Udosen AM, Glen E, Ogbudu S, Nkposong E. Incidence of leaving against medical advice (LAMA) among patient admitted at the accident and emergency unit of the University of Calabar Teaching Hospital, Calabar, Nigeria. Niger J Clin Pract. 2006;9(2):120-3.

22. Odelowo EO. Factors affecting morbidity and mortality from road traffic accidents: a Nigeria periurban study. Afr J Med Sci. 1993;22(2):69-74.
23. Eze B, Agu K, Nwosu J. Discharge against medical advice at a tertiary centre in southeastern Nigeria: sociodemographic and clinical dimensions. Patient Intell. 2010;2:27-31.

24. Ordinioha B. Incidence and reasons for Discharge Against Medical Advice in a tertiary health care facility in Port Harcourt, south-south Nigeria. J Community Med Prim Health Care. 2013;25(2):53-8.

Cite this article as: Ogunrewo TO, Magbagbeola OA, Oladejo ST, Allen-Taylor A. Incidence and reasons for leave against medical advice among orthopedic and trauma patients at the university college hospital Ibadan. Int J Res Orthop 2021;7:15. 